\title{
Interesses e recursos na rede de poder láctea: uma abordagem estrutural ${ }^{1}$
}

\author{
Jeovan de Carvalho Figueiredo ${ }^{2}$
}

RESUMO: As redes de recursos de poder são uma abrangente caracterização das relações entre os interesses público e privado, que dão conta das relações de troca entre o governo e a sociedade civil. Os diferentes arranjos estruturais das redes geram diferentes resultados, no que tange às possibilidades do processo político e da interação estratégica. O presente estudo tem como objetivo investigar como a estrutura da rede influencia os resultados obtidos pelos atores nela inseridos. As características estruturais da rede analisada mostram um arranjo organizacional próximo à noção de rede difusa, ou seja, mais instável, aberta e pouco institucionalizada. Como consequência, a relação de poder entre os atores é desigual, dado que os participantes têm recursos limitados e acesso restrito à formulação e implementação de políticas. Duas constatações derivam da estrutura observada na rede láctea sul-mato-grossense: os resultados políticos somente foram obtidos por não ameaçarem os interesses dos grupos econômicos que detêm recursos diferenciados, traduzidos em maior poder de barganha; e a implementação da política ocorreu descolada de sua formulação, sendo que a ação estratégica dos atores interessados não foi suficiente para garantir o alcance das metas inicialmente estabelecidas.

PALAVRAS-CHAVE: Recursos organizacionais, redes, institucionalismo, leite, Mato Grosso do Sul.

ABSTRACT: The policy network framework suggests a characterization of the relations between public and private interests, that permit understand the exchanges between the government and the civil society. The different structural arrangements of the policy networks generate different results, with different possibilities of political processes and strategic interactions. The present study explores how structure can define results aimed at network members. The structural characteristics of the analyzed network demonstrate a organizational arrangement similar to the diffuse network, understood as an unstable, opened and less institutionalized one. As consequence, the relation between the actors is defined by limited resources and restricted access to the formularization and implementation of politics. Two results derive from the structure observed in the dairy policy network analyzed: a) the political results only emerged by not threatening the interests of the economic groups that hold different kinds of resources, what means greater bargaining power; and b) the implementation of the politics occurred uncoupled of its original plan, since the strategic action of the interested actors was not enough to guarantee the objectives defined during the process.

KEYWORDS: Organizational resources, network, institutionalism, milk, Mato Grosso do Sul.

\footnotetext{
${ }^{1} \mathrm{O}$ autor agradece aos pareceristas dos Cadernos de Gestão Pública e Cidadania as críticas e as sugestões feitas à versão original do texto, bem como as contribuições anteriormente recebidas de discussões com Luiz Fernando Paulillo, Hildo Meirelles, Mauro Rocha Côrtes e João Mario Csillag. Eventuais omissões e falhas permanecem sob a responsabilidade do autor.

${ }^{2}$ Professor da Escola de Administração de Empresas de São Paulo da Fundação Getulio Vargas. Doutor em Administração de Empresas pela FGV-EAESP. E-mail: jeovan.figueiredo@fgv.br
} 


\section{Introdução}

Na maior parte das democracias liberais contemporâneas, é possível caracterizar a sociedade como altamente complexa e fragmentada. Decorre disto a existência de um grande número de grupos de interesse em interação com o governo. Nesse cenário, como indicam Rhodes e Marsh (1992), a elaboração de políticas toma lugar em uma variedade de redes caracterizadas pelas relações estreitas entre os interesses particulares e as diferentes esferas governamentais.

Nos últimos anos, a literatura sobre organizações em rede tem sido bastante profícua. Autores vinculados a Economia, Administração, Sociologia e Ciência Política têm produzido interessantes trabalhos sobre essa questão. Obviamente, as abordagens diferem no modo como o problema é tratado, enfatizando, assim, variáveis e perspectivas que podem, a partir do referencial teórico adotado, explicar melhor o fenômeno que se deseja tratar.

A contribuição do neoinstitucionalismo histórico para a análise de políticas públicas é a atribuição de importância ao processo histórico e, ainda, a proposição da existência de dependência entre setores e subsetores econômicos e políticos. Esses elementos estão presentes na discussão de aspectos como a dominação e a preservação do poder, a representação de interesses públicos e privados e a exclusão de interesses que afetam alguns atores na realização de políticas públicas (HALL e TAYLOR, 1996).

O presente estudo tem como objetivo investigar como a estrutura da rede influencia os resultados obtidos pelos atores nela inseridos. O resultado da interação é a inclusão do leite pasteurizado tipo C nas aquisições do Governo Estadual de Mato Grosso do Sul, destinadas a um programa social específico, o Programa de Segurança Alimentar e Nutricional. Apesar de esse resultado ser tratado na análise, a ênfase recai no processo de interação, pois este pode ser mais central que seus resultados (MARCH e OLSEN, 1993).

Neste trabalho, buscou-se ainda determinar os interesses e as expectativas dos atores envolvidos na rede e compreender o uso de recursos diferenciados na interação estratégica. A variável explicativa deste estudo é definida pelos recursos de poder dos atores, dado que a interdependência de recursos é o mais importante fator distintivo das redes interorganizacionais (PAULILLO, 2000) e sua análise permite avançar no conhecimento sobre as interações dos atores públicos e privados. 
Mas um foco voltado somente para a interdependência de recursos é insuficiente para explicar o fenômeno estudado. A análise deve, também, abranger a forma como as redes tornam-se institucionalizadas. A premissa adotada é que as ações dos membros da rede, no decorrer do tempo, tornam-se mais ou menos influenciadas pela ideologia, regras, rotinas, princípios e normas (DAUGBJERB, 1997). Desse modo, o caráter estrutural da rede assume importância significativa, por englobar a análise da interdependência de recursos e o processo de institucionalização da rede.

O presente artigo encontra-se dividido em cinco partes. Após esta breve introdução, foi revisitada na segunda parte a literatura de policy networks, ${ }^{3}$ cujas proposições permitem lidar com as interações entre o interesse público e privado. Esta seção apresenta e discute as contribuições institucionais para o estudo das redes, com maior ênfase nos aspectos relacionados à sua estrutura, e os limites decorrentes nas interações estabelecidas entre os atores inseridos na rede. Foi resgatada, na terceira parte, a discussão sobre o mercado político e a posição privilegiada das empresas em sociedades de iniciativa privada orientadas para o mercado. $\mathrm{Na}$ quarta parte, algumas evidências empíricas foram apresentadas e, à guisa de conclusão, na quinta são apresentadas as considerações finais.

\section{Atores, recursos e políticas públicas}

A abordagem institucional, originalmente desenvolvida nos trabalhos de Veblen (1975), Commons (1934) e, posteriormente, Ayres (1962), tratava as instituições ${ }^{4}$ como variáveis explicativas dadas. Para compreender os fenômenos sociais, políticos e econômicos atuais, o pensamento da "escola antiga” foi alterado em suas proposições teóricas a respeito da natureza das instituições, tomando-as agora como variáveis que se originam e são alteradas por meio da ação humana. Os novos institucionalistas consideram, portanto, que instituições importam e, além de serem construídas socialmente, podem também ser modificadas pelos atores.

\footnotetext{
${ }^{3}$ A abordagem de policy network tem sido tratada nos desenvolvimentos teóricos e empíricos de pesquisadores nacionais como rede política ou rede de poder (PAULILLO, 2000; 2002), e ainda como rede de política pública ou rede de ação pública (ROMANO, 1999). Apesar da variedade de expressões cunhadas no idioma nacional, todas pretendem referir-se ao conceito teórico consubstanciado principalmente na literatura da Ciência Política, que será retomado na próxima seção deste trabalho. Neste estudo, será adotado o termo rede de poder para identificar a noção de policy network.

${ }^{4}$ As instituições são definidas como “(...) regras formais e informais, rotinas, normas e convenções cristalizadas na estrutura da comunidade política e da economia política” (HALL e TAYLOR, 1996, p. 938).
} 
Três grandes correntes consolidam o pensamento institucional contemporâneo: o histórico, o da escolha racional e o sociológico. Ao examinar essas correntes, como o fazem Hall e Taylor (1996), verifica-se que o compromisso de pesquisa vinculado ao neoinstitucionalismo histórico recai em determinar o modo pelo qual as instituições distribuem poder de modo desigual entre os grupos sociais. É assumido, portanto, um mundo no qual instituições dão a alguns grupos ou interesses acesso descomedido ao processo de tomada de decisão, e a ênfase recai, assim, no modo como os resultados do processo favorecem alguns grupos em relação a outros.

Conhecendo o modo pelo qual instituições distribuem poder desigualmente entre grupos sociais, pode-se prever como será a alocação de benefícios entre grupos demandantes. O resultado será caracterizado pela notória prevalência dos interesses daqueles atores que dispõem de recursos de poder capazes de aumentar a dependência dos outros atores. Isto se dá porque o pressuposto básico das relações em rede é que um grupo é dependente dos recursos controlados por outro grupo, o que faz com que os lucros sejam provenientes da combinação conjunta de recursos (POWELL, 1990).

De fato, atores políticos criam uma rede de poder quando permutam recursos regularmente. Qualquer organização que é inserida nesse processo de trocas torna-se dependente dos recursos de outras organizações (DAUGBJERG, 1999). As redes emergem de considerações estratégicas de atores públicos e privados, já que cada um deles irá dispor de seus recursos - sejam eles legais-constitucionais, financeiros, políticos, ou informacionais para maximizar sua influência sobre os resultados, enquanto procuram tornarse menos dependentes dos outros atores (RHODES e MARSH, 1990).

Nesse contexto, as análises de redes de poder enfatizam o caráter relacional do poder, entendido a partir da visão de poder como “(...) recurso ou capacidade distribuído de forma diferenciada, e que se for empregado com o devido grau de habilidade estratégica e tática, produz e reproduz relações hierarquicamente estruturadas de autonomia e dependência” (REED, 1998, p. 75).

O poder não é, portanto, uma coisa ou a sua posse, e sim uma relação entre pessoas. A implicação disto resulta, ainda, no caráter potencial do poder, uma vez que atores mais poderosos (o que implica a posse de recursos de poder diferenciados) podem ou não exercêlo, bastando apenas para isto o cálculo estratégico empregado na consecução de seus 
objetivos. Dowding (1995) ainda argumenta que o poder de um ator depende do poder dos outros atores, e que o tipo de relação entre eles é definido pelos seus recursos.

Os recursos que os atores podem dispor em suas relações de poder indicam a sua capacidade de interferência nas decisões de outros atores em determinado contexto ou entorno. Assim, a estratégia dos atores em uma rede de poder será pautada na exploração dos recursos e capacidades diante de uma situação relacional específica. Esses recursos podem ser classificados, como indica o Quadro 1, em constitucionais, políticos, financeiros, tecnológicos, organizacionais e jurídicos.

Quadro 1 - Classificação e exemplos de recursos em redes de poder

\begin{tabular}{|l|l|}
\hline Grupo de recursos & \multicolumn{1}{|c|}{ Exemplos } \\
\hline Constitucionais & Regras e normas legitimadas. \\
\hline Políticos & $\begin{array}{l}\text { Status público atribuído pelo Estado, poder de representação de um ator } \\
\text { coletivo, poder de aglutinação de um ator coletivo. }\end{array}$ \\
\hline Financeiros & $\begin{array}{l}\text { Financiamento adequado, incentivo fiscal modificado ou concedido, } \\
\text { subsídio modificado ou concedido, comissões sobre escala de produção, } \\
\text { cotas promocionais. }\end{array}$ \\
\hline Tecnológicos & $\begin{array}{l}\text { Conhecimento adquirido, tecnologias gerenciais e da informação } \\
\text { transferidas, processos e matérias-primas específicas. }\end{array}$ \\
\hline Organizacionais & $\begin{array}{l}\text { Infraestrutura institucional (institutos de pesquisas, centros de } \\
\text { treinamento, agências de marketing etc.), informações compartilhadas e } \\
\text { propagadas, parcerias, consórcios, informações ocultadas, proximidade de } \\
\text { fornecedores, terceirização, subcontratação, utilização da marca. }\end{array}$ \\
\hline Jurídicos & $\begin{array}{l}\text { Direitos de propriedade intelectual, recursos sobre anti-dumping, } \\
\text { ajuizamento de ações. }\end{array}$ \\
\hline
\end{tabular}

Fonte: Adaptado de Paulillo (2002, p. 43).

A definição de rede de poder é construída por Rhodes (1986) com um enfoque estrutural. Assim, as características estruturais das redes vão definir um conjunto de redes que pode ser distribuído em um continuum entre dois pólos, definidos pelas comunidades políticas e pelas redes difusas, como indica o Quadro 2. Essas características estruturais são definidas pela forma como os atores públicos e privados (coletivos e individuais) interagem e, ainda, pela distribuição de recursos entre os membros e as relações hierárquicas de autonomia e dependência. 
Quadro 2 - O continuum entre a comunidade política e a rede difusa

\begin{tabular}{|l|l|l|}
\hline & Comunidade Política & Rede Difusa \\
\hline Número de membros & Limitado & Grande número de membros \\
\hline Valores dos atores & Compartilhados & Distintos \\
\hline Objetivos da integração & Barganha e negociação & Consulta \\
\hline Interação & Frequente & Instável \\
\hline Grau de Interdependência & Amplo & Limitado \\
\hline Recursos dos atores & Equivalentes & Desiguais \\
\hline Definição dos limites da rede & Reconhecimento mútuo & Livre entrada e saída \\
\hline Institucionalização & $\begin{array}{l}\text { Consenso na política, nos } \\
\text { princípios e procedimentos para } \\
\text { tratar dos problemas políticos }\end{array}$ & $\begin{array}{l}\text { Conflito na política, nos } \\
\text { princípios e procedimentos para } \\
\text { tratar dos problemas políticos }\end{array}$ \\
\hline
\end{tabular}

Fonte: Adaptado de Rhodes e Marsh (1990), Blom-Hansen (1997) e Dowding (2001).

A noção de comunidade política, de acordo com Rhodes e Marsh (1990), está voltada para as relações pessoais entre os maiores atores políticos e administrativos, que em alguns momentos estão em conflito, frequentemente estão em acordo, mas estão sempre em contato e operam como uma rede participativa. A premissa subjacente é que os atores nessa rede compartilham premissas comuns, o que torna mais propício o acordo e o consenso, dado que apenas algumas opções estão disponíveis. Por outro lado, a rede difusa é caracterizada por um grande número de participantes, um grau muito limitado de interdependência e, consequentemente, muitas opções de políticas são inseridas na agenda.

Os dois principais méritos da análise de redes de poder, segundo Daugbjerg (1997), são: a) a ênfase na interdependência de recursos, como força crucial por trás do processo político; e b) a ênfase na variação das relações entre governo e grupos de interesse, indicada no continuum entre comunidade política e rede difusa.

Waarden (1992) afirma que as principais variáveis envolvidas na análise de redes de poder são o número e o tipo de atores sociais envolvidos, a função principal da rede e o equilíbrio de poder. O número de participantes determina o tamanho da rede. Por sua vez, a natureza da rede será definida pelo tipo de atores envolvidos no processo político. Organizações privadas e órgãos governamentais normalmente são membros da rede. Assim, a configuração é definida pela participação de associações de interesses, partidos políticos, organizações científicas, específicas a um setor ou mesmo trans-setoriais.

As estruturas em redes não possuem objetivos próprios. Os atores sim, e dependendo desses objetivos, as redes assumem várias funções, tais como a consulta (ou troca de informações), 
a negociação (ou troca de recursos), a coordenação e mesmo a cooperação na formação, implementação e legitimação da política pública. Dessa forma, o conceito de função estabelece a ponte entre a perspectiva do "ator” e da "estrutura” na análise de redes. Nessa perspectiva, é possível caracterizar a distribuição de poder entre os agentes, que é dada como uma função da distribuição de recursos e necessidades entre os atores.

Alguns autores, como Marsh e Smith (2000, p. 6), defendem que os resultados políticos não podem ser explicados unicamente pela estrutura da rede. Eles são resultado das ações de sujeitos que calculam estrategicamente. Para defender esse ponto de vista, os autores recorrem a três argumentos: a) os interesses ou preferências dos membros de uma rede não podem se definidos meramente nos termos em que ocorre a associação na rede; b) os constrangimentos (ou oportunidades) para uma ação dos agentes que irá derivar-se da estrutura da rede não acontece automaticamente, uma vez que ela depende da construção discursiva desses constrangimentos ou oportunidades pelos atores; e c) os membros da rede têm habilidades que afetam suas capacidades de usufruir as oportunidades ou negociar constrangimentos.

Entretanto, se o foco da análise for o comportamento individual, então, necessariamente, o conceito geral de rede se torna menos útil. O resultado disto é que a teoria terá menos (ou nenhuma) chance de ser rigorosa, dado o grau de detalhamento necessário para generalizar os resultados para as redes de poder (RHODES e MARSH, 1990). Assim, é assumida a premissa de Dowding (2001), que pressupõe serem as características estruturais das redes causadoras de certos tipos de resultados políticos, e que o detalhamento desses resultados é o que permite o mapeamento de estruturas de poder.

Tendo a literatura de redes de poder um caráter interdisciplinar, há uma amplitude de terminologias, definições mutuamente exclusivas e, especialmente, diversos níveis de análise. A reserva de Rhodes e Marsh (1990), derivada dessa consideração, faz saber que quando a unidade e o nível de análise variam daqueles já amplamente definidos na literatura, é necessário adotar um uso cauteloso do conceito. Assim, mesmo focalizando um macro-objeto como a reforma da política agrícola da Comunidade Européia, Daugbjerg (1997) enfatiza a pertinência da análise de redes de poder para compreender o poder estrutural (SMITH, 1990) e a vantagem de alguns interesses sobre outros, dado que o nível macro é definido como o contexto institucional no qual as redes estão cristalizadas. 
A pertinência da análise realizada neste estudo provém da adequação do objeto em pauta às variáveis tratadas em nível meso. Como mostra o Quadro 3, diversos autores têm reforçado a distinção entre os níveis analíticos, colocando ênfase nas questões que emergem em cada nível, enquanto compromisso de pesquisa, e reafirmando as possibilidades de análise de redes em um nível intermediário entre o micro e o macro. Entretanto, como em todo esforço de classificação, há uma área cinzenta na delimitação entre os níveis, e os casos em que as distinções são claras refletem a particularidade, e não a generalidade.

O conceito de redes em nível meso é definido por Rhodes e Marsh (1990) em dois sentidos: o primeiro enfatiza as relações estruturais entre organizações políticas como o elemento crucial em redes, mais do que as relações interpessoais entre indivíduos e organizações. O segundo ressalta a existência de redes em níveis subsetoriais. De fato, Rhodes (1986) já havia preconizado a necessidade de focar a análise na variedade de articulações possíveis entre as diferentes posições estruturais assumidas por organizações políticas e governamentais. As relações entre essas organizações políticas - ou grupos de interesse - e as agências governamentais podem ser compreendidas por meio da análise de redes, formadas enquanto arranjos organizacionais que facilitam essa intermediação (DAUGBJERG, 1997).

\section{Quadro 3 - Questões e diferentes níveis de análise}

\begin{tabular}{|l|l|l|l|}
\hline \multicolumn{1}{|c|}{ Proponentes } & \multicolumn{1}{|c|}{ Nível Macro } & Nível Meso & \multicolumn{1}{c|}{ Nível Micro } \\
\hline Rhodes (1986) & $\begin{array}{l}\text { Mudanças nas } \\
\text { características do } \\
\text { governo nacional }\end{array}$ & Redes de poder & $\begin{array}{l}\text { Comportamento de } \\
\text { atores particulares } \\
\text { (indivíduos ou } \\
\text { organizações) }\end{array}$ \\
\hline Rhodes e Marsh (1990) & $\begin{array}{l}\text { Discussão sobre a } \\
\text { distribuição de poder } \\
\text { nas sociedades } \\
\text { contemporâneas }\end{array}$ & Redes de poder & $\begin{array}{l}\text { Papel dos interesses } \\
\text { privados e do governo } \\
\text { em relação a decisões } \\
\text { políticas específicas }\end{array}$ \\
\hline Evans (2001) & $\begin{array}{l}\text { Características do } \\
\text { sistema internacional e } \\
\text { do sistema político }\end{array}$ & Redes de poder & $\begin{array}{l}\text { Atitudes e } \\
\text { comportamentos } \\
\text { individuais }\end{array}$ \\
\hline
\end{tabular}

Evans (2001) afirma que conceitos de nível meso, como a análise de redes pressupõe, são úteis para delinear os caminhos pelos quais subsistemas políticos são desenvolvidos. Tratase, sobretudo, de um reconhecimento de que a elaboração de muitas políticas recentes é 
realizada por meio de redes com múltiplas camadas e com singular capacidade de autoorganização.

A premissa adotada neste estudo é que o Estado é um ator relevante na arena onde se dá o processo de interação de atores políticos e econômicos. Os embates ocorrerão motivados pelos interesses e valores conflitantes de organizações governamentais e grupos de interesses privados. As redes, nesse contexto, tornam-se uma abrangente caracterização das relações entre o interesse público e o privado, e dão conta das relações de troca entre o governo e as organizações da sociedade civil, já que suas proposições conceituais são adequadas para a análise da formulação e implementação de políticas públicas.

\section{O político como empresário e o empresário como funcionário público}

A democracia, como forma de regime político de governo, é um conjunto de regras implícitas e explícitas que regem as relações entre os atores sociais em um contexto histórico dado. Sendo a democracia um produto da aliança de poder que se forma na sociedade em determinado momento histórico, e sendo o poder a capacidade de alguns de impor sua vontade sobre os outros, pressupõe-se a existência de uma relação de poder baseada na legitimidade.

Quando o poder é percebido como legítimo pelos indivíduos de uma comunidade, ele dá forma a algum tipo de autoridade. Assim, haverá uma estrutura de governo, onde autoridades e grupos subordinados estabelecerão uma relação de dependência. A dimensão política resultante implica a formação de coalizões e grupos de interesse, que produzirão processos de elaboração de políticas, onde as regras e normas dependerão do livre jogo de forças no mercado político.

O pioneiro na construção dessa perspectiva de oferta e demanda para compreender a política foi Weber (1992). Segundo ele, o líder político deverá dar conta dos interesses que conformaram a aliança de poder no momento em que for levar adiante políticas públicas. Tal argumento é válido em um cenário de dominação racional-legal, onde o governante sustenta seu poder por meio da legitimidade. Ora, a legitimidade do governante é uma função do êxito de suas principais políticas. Desse modo, quanto maior o sucesso de suas políticas, maior é sua legitimidade.

CADERNOS GESTÃO PÚBLICA E CIDADANIA, V. 14, N. 54 - JAN./JUNHO DE 2009 
Retomada por Schumpeter (1984), a analogia entre mercado e democracia avançou para uma concepção econômica da democracia. Se Weber propusera uma metáfora na qual supostamente em todas as economias - com exceção das mais primitivas - a oferta dos bens públicos, e os meios para organizá-la, poderiam ser considerados como um monopólio natural, Schumpeter propôs uma analogia em que na democracia, tal qual no mercado, haveria uma competição de “empresários políticos” pela preferência dos eleitores (consumidores de bens públicos). A livre competição pelo voto livre é, portanto, uma das mais originais contribuições da concepção schumpeteriana de democracia.

O êxito das políticas governamentais é fundamental para esses empresários políticos. Sendo a função primária do voto de um eleitor, em um regime democrático, a "produção" de um governo, os partidos políticos procuram conquistar a confiança dos eleitores, de modo que prevaleçam sobre os outros partidos e cheguem ao poder. Sendo essa confiança obtida a partir dos resultados e, portanto, da competência dos governantes, não haverá um monopólio no regime democrático. Essa assertiva somente se mantém sob a alegação de Schumpeter de que a democracia é um método político, um tipo de arranjo institucional para sejam alcançadas decisões políticas e, portanto, não pode ser um fim em si mesma, não importando as decisões que produza sob condições históricas dadas (SCHUMPETER, 1984, p. 304). Desse modo, pressupõe-se a existência de consenso em relação aos meios pelos quais os eleitores produzirão governos.

A noção de mercado político está ainda fortemente ligada ao trabalho de North (1990). Sua caracterização de organizações deixa claro que “[elas] não só investem diretamente na aquisição de habilidades e conhecimentos como também canalizam indiretamente (através do processo político) os investimentos públicos para as áreas de especialização que, em sua visão, aumentariam suas perspectivas de sobrevivência” (NORTH, 1990, p. 14). Essa canalização de investimentos públicos corresponde ao que Lindblom (1979, p. 18) chamou de "posição privilegiada da empresa”. Segundo ele, as empresas são mais importantes e mais ricas que os indivíduos na sociedade e têm direitos que são negados a esses indivíduos. Além disso, o impacto político das empresas difere e torna menor o do cidadão comum.

O papel político do empresário é substancial, dado que em grande parte das democracias liberais, os executivos respondem por questões que não fazem parte da esfera de 
competência do governo. Essas questões referem-se a aspectos da produção e distribuição de bens e riquezas. Portanto, em algum grau, os homens de negócios tomam decisões de política pública. São tomadores de decisão sujeitos a um importante controle pelos consumidores, que interferem em questões como o que será produzido e em qual quantidade.

Por sua vez, as empresas também exercem controle sobre o governo. Mas esse grau de controle empresarial não encontra equivalente em qualquer outro grupo de cidadãos. Isto se dá porque os preços, os empregos, a produção, o crescimento econômico e a segurança econômica da sociedade dependem, sobremaneira, da atividade empresarial. Assim, “(...) os empresários em geral, e os executivos em particular, assumem um papel privilegiado no Governo que, parece razoável dizer, não é igualado por qualquer outro grupo de liderança que não os próprios funcionários do Governo” (LINDBLOM, 1979, p. 196). É percebida, portanto, a dependência do governo do bom desempenho da economia, traduzido em privilégios às empresas, dado que são elas quem realizam os negócios. Isto é reforçado por Rhodes e Marsh (1992), que citam diversos estudos de caso onde os grupos produtivos e profissionais dominam as redes políticas, juntamente com o governo, e outros grupos exercem papel pouco significativo.

Por fim, vale a ressalva de Bobbio, que trata a metáfora do mercado político como "uma analogia que deve ser considerada com a máxima cautela, tantas são as afinidades aparentes e as diferenças substanciais” (2000, p. 138).

\section{Evidências empíricas na análise dos interesses e da interdependência de recursos}

Para a elaboração desta análise empírica, foram consultados dados obtidos a partir de fontes secundárias, como o relatório final da Comissão Parlamentar de Inquérito (CPI) instaurada pela Assembléia Legislativa do Estado de Mato Grosso do Sul, que investigou os baixos preços pagos aos pecuaristas leiteiros nos últimos meses de 2001, e o relatório de pesquisa sobre os aspectos econômicos do encadeamento produtivo lácteo sul-mato-grossense, elaborado por Michels, Sabadin e Oliveira (2003). Como ainda houve questões não respondidas após o levantamento desses dados, recorreu-se a fontes primárias, como entrevistas não estruturadas com um pesquisador da Embrapa Gado de Leite e um analista administrativo do Governo do Estado de Mato Grosso do Sul, integrante da equipe 
responsável pelo Programa de Segurança Alimentar e Nutricional. Houve ainda um momento de observação em um dos encontros da câmara setorial, que congrega representantes dos atores públicos e privados.

O que foi realizado nessa etapa é preconizado por Dowding (2001), que indica a necessidade de discutir questões sobre as relações entre as características estruturais da rede analisada para compreender os mecanismos causais subjacentes que conduzem a diferentes tipos de resultados políticos. Assim, a análise das características da rede permitiu apontar inferências causais e descritivas, relacionadas ao fenômeno estudado.

O resultado analisado neste estudo corresponde à implementação de uma política de aquisição de leite pelo Governo do Estado de Mato Grosso do Sul. Esse resultado decorre de um processo iniciado durante uma grave crise ${ }^{5}$ que abateu o setor lácteo em 2001 e motivou a instauração de Comissões Parlamentares de Inquérito em estados como Paraná, Rio Grande do Sul, Mato Grosso do Sul, Santa Catarina e Goiás, visando à investigação das causas da baixa remuneração recebida pelos pecuaristas leiteiros nesses estados.

Para analisar a rede em questão, é preciso compreender a histórica dependência entre os interesses dos produtores de leite e do Estado. Desde a década de 1930 até o início da década de 1990, o setor lácteo foi alvo de forte atuação do Estado, seja por meio de regulamentações, ou por meio de subsídios. Mas a partir da abertura econômica, emergiram novas arenas, setoriais e regionais, onde os atores do setor lácteo passaram a se articular. Com uma ênfase maior no aspecto estrutural das redes de poder, e menos nos aspectos simbólicos e subjetivos, a próxima seção explora uma arena específica onde emergiu a rede analisada.

\footnotetext{
${ }^{5}$ A crise supracitada ocorreu no final de 2001, período no qual o Governo Federal adotou uma política de desvalorização do Real que vinha desestimulando as importações. Paralelamente, houve um processo antidumping que obrigou grandes empresas exportadoras a fixar preços mínimos em negócios com o Brasil. O resultado foi que no início de 2002 as importações caíram em volume. A expectativa era o aumento do valor pago aos pecuaristas, proveniente da diminuição da oferta. Entretanto, essa expectativa não se confirmou, e o que ocorreu foi a justamente a diminuição do preço recebido por eles. Alguns dos fatores macroeconômicos que influenciaram esse cenário foram a crise energética e a consequente diminuição do emprego. Além disto, houve uma piora no mercado mundial lácteo, influenciada pelos atentados das torres gêmeas em 11 de setembro de 2001 (LIMA FILHO, FIGUEIREDO e PIRES NETO, 2003).
} 


\section{Análise estrutural da rede láctea sul-mato-grossense}

A análise da rede láctea sul-mato-grossense permite inferir a existência de uma arena regional, dada a interdependência de recursos entre os atores dessa rede. De fato, algumas evidências aclaram essa afirmação, tal como o fluxo de informações sobre questões relativas ao setor lácteo, que ocorre entre os atores coletivos. Durante a crise que abateu o setor lácteo, em 2001, os representantes dos produtores rurais se organizaram e distribuíram 1.500 litros de leite a organizações do terceiro setor. Esse protesto ocorreu junto ao prédio da Assembléia Legislativa e teve como objetivo ampliar a visibilidade das reivindicações dos produtores, sendo articulado pelo Sindicato Rural de Campo Grande (SRCG), pela Associação dos Criadores de Mato Grosso do Sul (Acrisul) e pela Federação de Agricultura de Mato Grosso do Sul (Famasul), por meio de sua Comissão Estadual do Leite, além de outras associações de produtores de leite com menor poder de aglutinação. Portanto, houve uma ação sincronizada e um objetivo compartilhado por esses atores, que era pressionar a classe política para a obtenção de recursos financeiros, traduzidos em aumento da demanda decorrente da aquisição governamental do produto lácteo in natura.

As evidências indicam que tal interesse foi manifestado pelos atores vinculados à produção primária do leite desde as primeiras audiências da CPI. Ainda na primeira audiência pública, ocorrida em 5 de dezembro de 2001, foi destacada, pelos produtores rurais das bacias leiteiras de Campo Grande e da região Centro Norte, a “importância (...) da inclusão do leite na merenda escolar” (MATO GROSSO DO SUL, 2002, p. 9, grifo nosso). Da mesma forma, na segunda audiência, ocorrida em 12 de dezembro de 2001, os produtores das regiões de Miranda, Dois Irmãos do Buriti, Batayporã, Naviraí e Amambaí ressaltaram a "necessidade (...) da inclusão do leite tipo C na merenda escolar e nas cestas básicas distribuídas à população, através de programas sociais do Governo do Estado” (id. loc. cit., grifo nosso).

A estratégia adotada pelos produtores rurais consistiu em enfatizar o alto preço do leite nas gôndolas dos supermercados e as condições pouco favoráveis de negociação com os laticínios. Os laticínios dispõem uma gama maior de recursos de poder que, efetivamente, diminuem o poder de negociação dos pecuaristas. A postergação de pagamentos, indicada em depoimentos à CPI, e as comissões sobre escalas de produção, com pagamento diferenciado para aqueles produtores que entregam maiores quantidades de leite, como 
acontece na região do Bolsão, revelam o predomínio do poder de alguns laticínios em suas relações com seus fornecedores de leite.

As grandes redes de supermercados dispõem de recursos financeiros, tecnológicos e organizacionais que as tornam os atores com maior poder no estabelecimento de preços e prazos de pagamento. Dessa forma, representantes dos laticínios informaram à CPI que “(...) as grandes redes de supermercados exigem descontos e bonificações abusivas para comprar os produtos dos laticínios. As indústrias alegam que se submetem a tais condições, porque necessitam dos supermercados para sobreviverem (...)” (MATO GROSSO DO SUL, 2002, p. 11).

Para compreender a interação estratégica entre esses atores, é necessário conhecer a estrutura da rede. Para tanto, não basta apenas uma descrição de como se processam as interações entre os atores. Como afirma Dowding (2001, p. 90-91), uma boa história descritiva poderia fornecer todas as respostas, mas o problema é que ela não pode demonstrar que está fornecendo essas respostas. Essa falha pode ocorrer de dois modos: a) as boas histórias descritivas poderiam não capturar todos os fatores causais relevantes e, entre esses fatores, poderiam estar os fatores cruciais para compreender a questão; e b) não importa quão boa seja a história descritiva, ela não poderia mostrar quais fatores causais são mais importantes. Assim, não importa quão detalhada e bem pesquisada seja a descrição, ela não pode substituir a especificação do modelo, que consiste na representação simplificada de processos sociais e instituições. O modelo, aqui utilizado, foi exposto anteriormente neste trabalho.

O número de atores coletivos na rede é significativo. Os representantes dos agentes produtivos são a Famasul, a Acrissul e os sindicatos rurais da capital e do interior. O representante da indústria é o Sindicato das Indústrias de Laticínios de Mato Grosso do Sul (Silems). As redes varejistas são representadas pela Associação Sul-mato-grossense de Supermercados (Amas). Os atores estatais, por sua vez, correspondem à Delegacia Federal de Agricultura em Mato Grosso do Sul (DFA-MS), ao Instituto de Desenvolvimento, Pesquisa e Extensão Rural (Idaterra), à Secretaria de Produção do Estado de Mato Grosso do Sul, por meio de sua Câmara Setorial do Leite, e a Agência de Defesa Sanitária Animal e Vegetal de Mato Grosso do Sul (Iagro). Entretanto, esses atores estatais tiveram um papel menor que o papel desempenhado pela Assembléia Legislativa de Mato Grosso do Sul, 
pois, durante a vigência das investigações da CPI, relevantes resultados políticos foram obtidos pelos atores privados.

Os atores produtivos da rede láctea sul-mato-grossense divergem quanto aos seus interesses. Os produtores rurais parecem ainda crer que as aquisições governamentais, a política de preços mínimos e o fornecimento de crédito subsidiado são os alicerces para a manutenção de sua atividade, como acontecia no passado. Como ficou evidenciado em estudos anteriores, o produtor de leite atua de modo isolado, não formando qualquer tipo de parceria ou ingressando em uma cooperativa (MERCOESTE, 2002). Portanto, não aumenta os seus recursos organizacionais e tecnológicos, dado que não obtém aumento de produtividade e/ou diferenciação de seu produto. Os laticínios e, em maior grau, as grandes redes varejistas, formulam estratégias baseadas no aumento da eficiência e produtividade. Como exemplos, os laticínios pagam maiores valores aos pecuaristas por maior qualidade e maior quantidade de leite fornecido, e os supermercados, em um cenário de forte competição, buscam ofertar aos seus clientes produtos com altos níveis de qualidade e baixos preços. Enquanto os pecuaristas aguardam ações governamentais, os laticínios e redes varejistas procuram fornecedores competitivos e capacitados tecnologicamente.

Os limites da rede podem ser considerados fracamente estabelecidos, o que permite aos atores individuais encontrarem relativa facilidade no acesso à rede. Assim, os maiores laticínios do Estado não foram representados pelo Silems, como ficou evidenciado nas audiências da CPI, mas agiram individualmente. Da mesma forma, cada grupo de supermercados pode facilmente interferir na rede se fizer uso de seus recursos, como a ameaça de aquisição de produtos lácteos de outros Estados.

Os objetivos da integração correspondem, principalmente, à busca de maiores recursos de poder, pelos produtores rurais, e manutenção do status quo, pelos laticínios e redes varejistas. O comportamento adversarial dos atores estimula a barganha por recursos, o que torna a integração instável, ocorrendo, assim, somente em algumas ocasiões específicas, como encontros setoriais e períodos de crise no setor.

O grau de interdependência dos recursos entre os atores é intermediário. Não é amplo, como ocorre nas denominadas redes produtivas, tampouco limitado, dado que os atores (principalmente produtivos) precisam de suporte mútuo para se manter na atividade. É, no mínimo, pouco crível supor que pecuaristas, laticínios e supermercados possam ter algum 
grau de equiparação do seu conjunto de recursos se os resultados econômicos desses atores diferem grandemente. Michels, Sabadin e Oliveira (2003) apontam a assimetria na apropriação de ganhos entre os atores produtivos, sendo que os pecuaristas obtêm 29,3\% do valor pago pelo consumidor final, os frigoríficos 50,6\%, e as redes de distribuição 20,7\%.

Apesar de trabalharem com menor margem na venda dos produtos lácteos, os supermercados obtêm ganhos significativos em função da estratégia adotada. Diminuindo o preço do leite, eles atraem consumidores que realizariam suas compras em padarias e, assim, aumentam o tráfego entre as gôndolas - já que a seção de laticínios é estrategicamente inserida no final da loja - ampliando desse modo as compras por impulso, ou não planejadas.

A rede láctea sul-mato-grossense é, também, pouco institucionalizada, dado o conflito entre os interesses dos atores. Há diversas racionalidades envolvidas, que estabelecem certas fronteiras entre as possíveis propostas de políticas. Algumas dessas fronteiras aparecem claramente delimitadas e codificadas em propostas de políticas públicas, tais como a concessão de incentivos fiscais para a instalação de indústrias de leite UHT e de leite em pó. Essa política beneficiaria principalmente os produtores, mas, possivelmente, afetaria negativamente os laticínios já instalados em Mato Grosso do Sul, pelo aumento do preço do leite in natura decorrente da diminuição da oferta.

Outras propostas de políticas, com limites cinzentos e ambíguos, estão sujeitas a todo tipo de contingências. Dado que as decisões de políticas públicas, segundo Skocpol (1992), podem ser entendidas como alocações de benefícios entre grupos demandantes, a inclusão do leite no programa social do governo favoreceu os pecuaristas, mas, também, os laticínios, pois é diretamente deles que o Governo do Estado adquire o produto. Assim, mesmo sendo duramente criticados nas sessões da CPI, pela imposição de seu poder de barganha na determinação do preço a ser pago pelo leite fornecido pelos produtores rurais, os laticínios se tornaram peça-chave na intervenção governamental. Isto pode ser explicado pelo poder de representação de seu ator coletivo, como será visto a seguir.

\section{Os resultados obtidos pelos atores na rede}

A análise estrutural da rede mostrou a existência de uma estrutura organizacional mais próxima da noção de rede difusa, principalmente no que tange à institucionalização da rede, 
frente ao conflito na elaboração e implementação de políticas. Os resultados do processo, portanto, não puderam ser obtidos exclusivamente na arena já estabelecida, a Câmara Setorial do Leite, mas tiveram que ser buscados em outra arena, mais próxima do mercado político de Weber e Schumpeter.

A CPI, para Guanabara (1999), não é somente um mecanismo pelo qual o Poder Legislativo pode manter certo controle sobre as ações do Poder Executivo, mas também é um meio de que os legisladores podem fazer uso para se manterem informados, de forma satisfatória, sobre os assuntos mais relevantes para o país, até mesmo como condição para um adequado desempenho de suas atividades.

Contudo, essa caracterização é insuficiente para dar conta da análise em pauta. É necessário explorar a natureza da CPI, enquanto instituição política. De acordo com March e Olsen (1993), as comissões parlamentares podem ser entendidas como cenários para a luta das forças sociais, mas, também, como conjuntos de procedimentos padronizados que definem e defendem interesses. Essa caracterização permite avançar na compreensão da CPI como arena e ator político.

As características das duas arenas são mostradas na Figura 1, segundo as dimensões caráter (ou natureza), objetivo, forma de divulgação das atividades, enfoque atribuído às ações, e os agentes beneficiados.

Figura 1 - Diferentes arenas da rede de recursos de poder territorial láctea
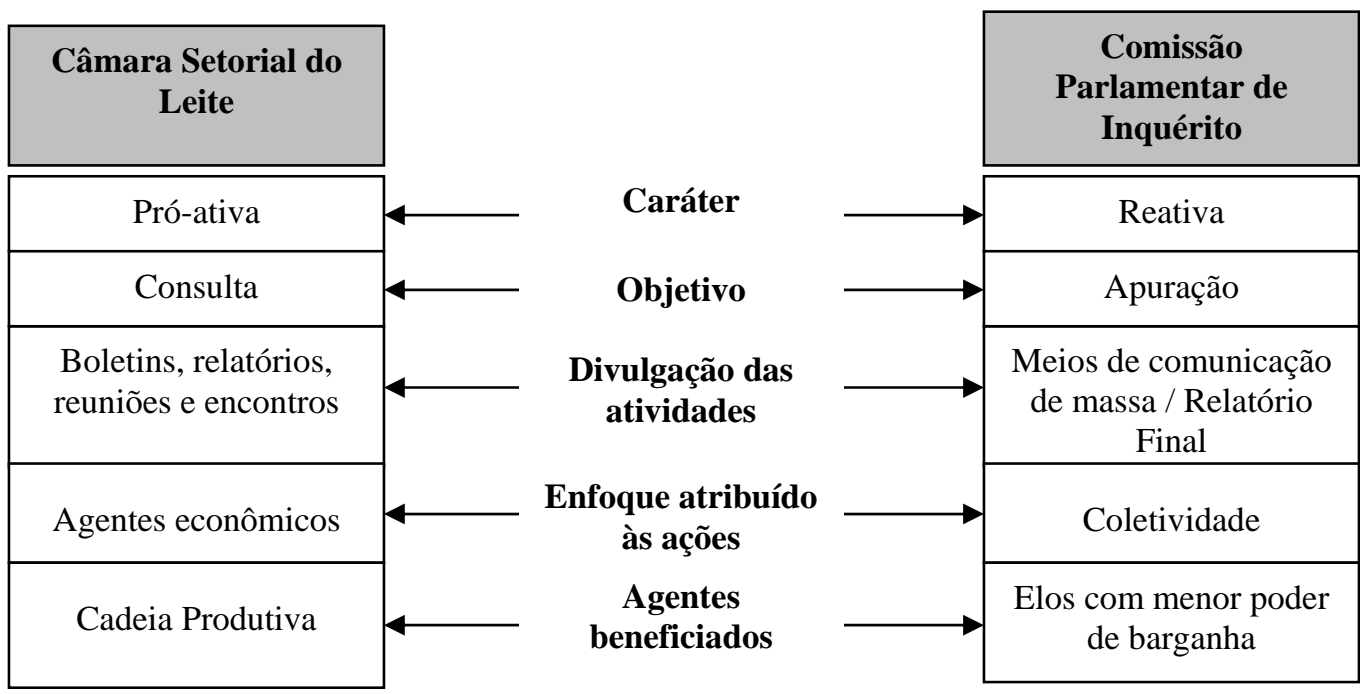

CADERNOS GESTÃO PÚBLICA E CIDADANIA, V. 14, N. 54 - JAN./JUNHO DE 2009 
Enquanto o suposto caráter sistêmico da Câmara Setorial do Leite enfatiza a consulta e prévia articulação dos agentes econômicos do encadeamento produtivo, a CPI é instaurada com o objetivo de apurar um fato determinado, tendo para tanto poderes próprios das autoridades judiciais. O interesse da apuração recai, portanto, nos acontecimentos relevantes para a vida pública e na ordem constitucional, legal, econômica e social do país. A exclusão de pecuaristas da atividade produtiva, em vista da ausência de ganhos suficientes para permanecer na atividade, torna-se, assim, assunto de interesse para os parlamentares, em vista dos possíveis problemas sociais decorrentes, tais como a migração de mão-de-obra com baixa qualificação para os centros urbanos, a diminuição da concorrência no elo responsável pela produção primária do leite, a escassez do produto e, ainda, a possível elevação dos preços, que tem como efeito a redução do consumo entre a população de baixa renda.

A forma como as informações são divulgadas nessas arenas diferem entre si. A cobertura, pelos meios de comunicação de massa, dos trabalhos da CPI faz com que a construção de classificações, inerente ao trabalho político, reflita de forma ampliada no espaço social, o que gera benefícios ou prejuízos aos membros da rede. Esse argumento é validado pelo movimento de algumas empresas responsáveis pela distribuição do leite, que diminuíram o preço do produto aos consumidores, após terem sido citadas, em uma audiência pública que antecedeu a instauração da CPI, como responsáveis pelo baixo preço recebido pelos produtores rurais (Correio do Estado, 26.10.2001; Folha do Povo, 30.10.2001). Contudo, o preço anterior foi retomado posteriormente.

O relatório final da CPI também é um importante elemento no processo, pois ele é, após a conclusão dos trabalhos da CPI, encaminhado à Mesa Diretora da Assembléia Legislativa para que possíveis providências possam ser tomadas. Esse documento também é encaminhado ao Ministério Público, para que haja, em casos específicos, a promoção da responsabilidade civil ou criminal dos agentes investigados.

A conclusão do relatório final da CPI do Leite apontou a existência de "distorções no mercado causadas por determinados elos da cadeia produtiva do leite com o intuito da locupletação em detrimento dos produtores rurais” (MATO GROSSO DO SUL, 2001). Os elos que supostamente ampliaram suas margens de lucro às custas dos pecuaristas não são diretamente apontados no relatório final, evidenciando, assim, a já premente dependência 
do Governo Estadual da capacidade de representação do ator coletivo da indústria de laticínios, até então um ator com pouco peso nas discussões na rede.

Esse ator adquiriu maior importância no processo após a inclusão do leite no Programa de Segurança Alimentar e Nutricional (PSAN) do Governo Estadual. Ao ser identificado como a organização coletiva capaz de dar sustentação à política, já que se trata de um representante válido dos interesses da indústria, o Sindicato das Indústrias de Laticínios de Mato Grosso do Sul (Silems) assumiu o papel de orquestrar os atores individuais nos procedimentos necessários para o fornecimento do leite à Central de Compras do Governo de Mato Grosso do Sul. A implementação da solução formulada no âmbito da CPI encampou, portanto, alguns dos atores vistos como responsáveis pelo problema, dado que seus recursos eram necessários para dar sustentação às mudanças no programa governamental.

A inclusão do leite tipo C pasteurizado no PSAN, adquirido de pecuaristas e laticínios sulmato-grossenses, foi um dos resultados gerados pela CPI. O volume inicial de leite fornecido às famílias atendidas pelo Programa, em setembro de 2002, era de 180 mil litros ao mês. Contudo, estipulou-se uma meta de compra, prevista para ser alcançada em dezembro de 2002, de 1 milhão de litros a cada mês.

Essa meta nunca foi atingida. De acordo com a Superintendência dos Programas de Inclusão Social do Governo do Estado de Mato Grosso do Sul, as aquisições do Governo estadual, nos vinte e quatro meses seguintes à inclusão do produto no programa, mantiveram a média de 218,67 mil litros de leite ao mês. Apesar de as aquisições darem-se preferencialmente de pequenos produtores rurais, o volume de leite adquirido dos sete laticínios fornecedores é insuficiente para modificar a dinâmica que rege as relações de poder e dependência nas transações efetuadas entre produtores e laticínios.

Lima Filho, Figueiredo e Pires Neto (2003) apontaram a dependência dos pequenos produtores sul-mato-grossenses em relação aos laticínios próximos, pois a alta perecibilidade do produto e a inexistência de tanques resfriadores, particulares ou comunitários, incentivam os pecuaristas a comercializarem sua produção em um curto intervalo de tempo, a saber, até as dez horas da manhã do mesmo dia em que houve a ordenha. Caso isto não ocorra, ela será totalmente perdida. Essa situação aumenta 
consideravelmente o poder de barganha da indústria, pois impõe a necessidade de produtores e laticínios estarem situados na mesma região, para que a transação ocorra.

Portanto, as aquisições de leite do Governo Estadual beneficiaram os produtores que estavam localizados próximos aos laticínios que fornecem leite para o PSAN. Eram seis laticínios situados na região de Campo Grande e um laticínio no município de Dourados. A Figura 2 mostra que essa distribuição beneficiou somente produtores de duas bacias de leite com o arranjo institucional elaborado no âmbito na CPI.

Figura 2 - Bacias de leite onde eram realizadas as aquisições governamentais (2004)

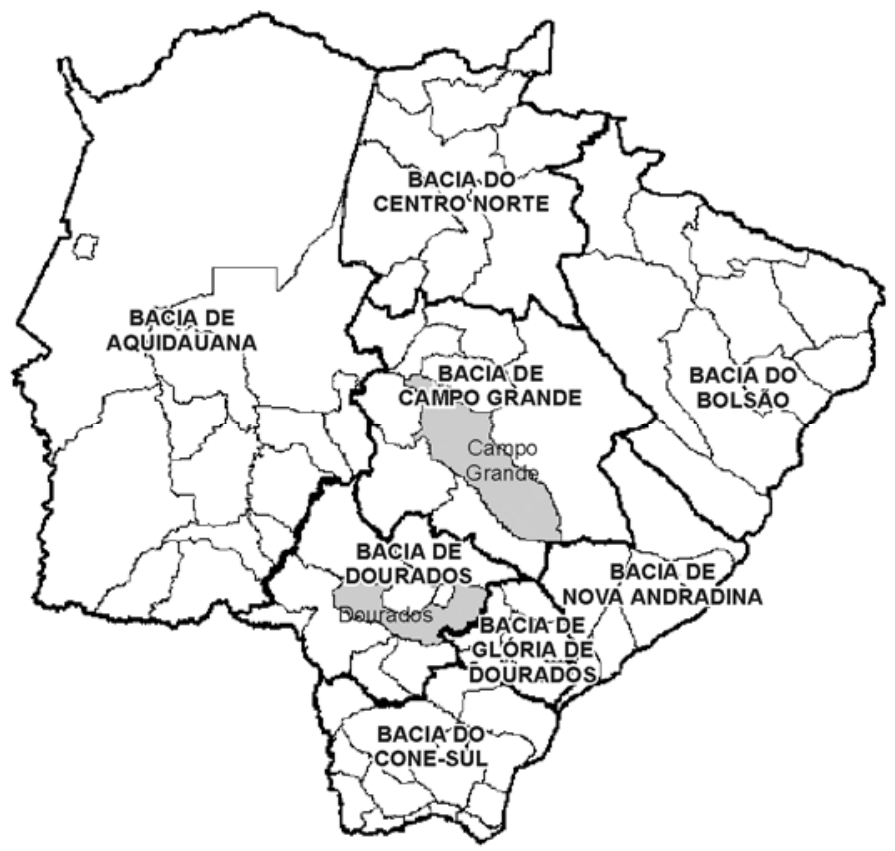

De acordo com Michels, Sabadin e Oliveira (2003), as bacias de Campo Grande e Dourados eram responsáveis por 17,28\% e 9,81\% da produção de leite do Estado. As duas respondiam, portanto, por 27,09\% do total produzido, o que equivale a 115,75 milhões de litros ao ano. A média das aquisições governamentais revela que, anualmente, era comprado pelo Governo Estadual um volume próximo a 2,27\% do total de leite produzido nas duas bacias leiteiras. Uma quantidade pouco significativa diante do principal problema que atinge o setor: a sazonalidade na produção, responsável pela variação de até 50\% entre o total produzido na safra e entressafra (MERCOESTE, 2002). 
O caráter subótimo dos resultados alcançados pelos atores inseridos na rede de poder láctea

é visível, mas perfeitamente compreensível à luz da teoria. A próxima seção deste trabalho apresenta algumas considerações finais, à guisa de conclusão.

\section{Considerações finais}

O fornecimento de leite para o Programa de Segurança Alimentar e Nutricional pode ser considerado o principal resultado do processo definido pelas interações dos atores da rede láctea territorial sul-mato-grossense. As preferências de diversos atores políticos, nesse sentido, tornaram-se evidentes já nas primeiras sessões da CPI do Leite, não sendo contestadas nesse propósito por qualquer outro ator público ou privado.

Como mostra a história, essas preferências parecem reproduzir situações passadas, não mais adequadas ao atual contexto social e econômico. Isto parece corroborar a afirmação de DiMaggio e Powel (1991), que são céticos em relação aos argumentos que assumem como soluções eficientes as instituições que persistem, dado que práticas organizacionais subótimas podem persistir por um grande período de tempo, argumento este que é transladado para as organizações, no trabalho de Meyer e Zucker (1989). Os autores demonstraram que em situações onde ocorre a convergência de interesses de atores que possuem elevada dependência de outros, tal qual ocorreu com os produtores rurais em relação aos laticínios, ocorrerá um incremento do poder efetivo do grupo que criou a coalizão. Mas o resultado usual desse esforço é a manutenção de níveis subótimos de desempenho organizacional, tal qual ocorreu com a organização em rede discutida neste estudo, ainda que a sua permanência ao longo do tempo tenha sido reforçada pelo esforço empreendido pelos atores da rede.

O presente trabalho mostrou que alguns pequenos produtores, mesmo produzindo em baixas escalas e com tecnologia rudimentar, obtiveram maior acesso a recursos financeiros, pelas vendas que passaram a realizar aos laticínios incluídos no rol de fornecedores dos produtos destinados ao programa social do Governo Estadual. Esses pecuaristas fizeram uso dos recursos políticos e organizacionais de seus atores coletivos e foram bem representados no mercado político, conseguindo, assim, obter resultados favoráveis a seus interesses na formulação da política de inclusão do leite tipo C pasteurizado no Programa de Segurança Alimentar e Nutricional. 
A distribuição de recursos entre os atores também afetou os resultados por eles obtidos. A posse de recursos diferenciados - principalmente financeiros, tecnológicos e organizacionais - permitiu aos segmentos indústria e distribuição manterem o curso das estratégias adotadas anteriormente à CPI.

As modificações referem-se apenas ao maior rigor no aspecto da regulação social, com a ampliação da inspeção de produtos lácteos consumidos pela população do Estado. Essa ênfase normativa é perfeitamente compreensível em decorrência da investigação proposta pela CPI, que efetivamente pauta-se nas regras formais como elemento principal das restrições impostas pelas "regras do jogo”.

Apesar dos resultados gerados pelo uso dos recursos políticos e organizacionais dos atores coletivos vinculados aos pecuaristas, tais recursos não foram suficientes para que o Governo do Estado cumprisse a meta estipulada no âmbito da CPI, de adquirir 1 milhão de litros de leite ao mês. A solução desenhada pelos parlamentares, em conjunto com os atores produtivos, esbarrou nas limitações impostas pela alocação de recursos estabelecida pelo Governo Estadual.

O não cumprimento da meta pode ser entendido como um resultado da interação dos atores na rede. As características da rede de poder territorial láctea indicam uma estrutura com elevado número de membros, o que condiz com os limites fracamente definidos da rede. Os valores dos membros são conflitantes e a integração instável, ocorrendo somente em situações específicas, como períodos de crise no setor. O grau de interdependência de recursos entre os membros da rede encontra-se em um nível intermediário. O principal objetivo de alguns atores na rede, principalmente os produtores rurais, é a aquisição de novos recursos. Esses atores buscam a interação, mas a rede continua pouco institucionalizada frente ao conflito de interesses com a indústria e o elo responsável pela distribuição.

As características estruturais dessa rede mostram um arranjo organizacional próximo à noção de rede difusa, ou seja, mais instável, aberta e pouco institucionalizada. Como consequência, a relação de poder nessa rede é desigual, dado que os participantes têm recursos limitados e acesso restrito à formulação e implementação de políticas. Duas constatações derivam da estrutura observada na rede láctea sul-mato-grossense: a) os resultados políticos somente foram obtidos por não ameaçarem os interesses dos grupos 
econômicos que detêm recursos diferenciados, traduzidos em maior poder de barganha; e b) a implementação da política ocorreu descolada de sua formulação, sendo que a ação estratégica dos atores interessados não foi suficiente para garantir o alcance das metas inicialmente estabelecidas.

\section{Referências}

AYRES, C. E. The theory of economic progress. 2nd ed. New York: Schocken, 1962.

BLOM-HANSEN, J. A "new institutional" perspective on policy networks. Public Administration, v. 75, n. 4, p. 669-693, 1997.

BOBBIO, N. O futuro da democracia. São Paulo: Paz e Terra, 2000.

COMMONS, J. R. Institutional economics. New York: Macmillan, 1934.

DAUGBJERG, C. Policy networks and agricultural policy reforms: explaining deregulation in Sweden and re-regulation in the European Community. Governance, v. 10, n. 2, p. 123142, 1997.

DAUGBJERG, C. Policy networks under pressure: pollution control, policy reforms and the power of farmers. Aldershot, UK: Ashgate, 1998.

DAUGBJERG, C. Reforming the CAP: policy networks and broader institutional structures. Journal of Common Market Studies, v. 37, n. 3, p. 407-428, 1999.

DIMAGGIO, P. J.; POWELL, W. W. Introduction. In: POWELL, W. W.; DIMAGGIO, P. J. (Org.) The new institutionalism in organizational analysis. Chicago: The University of Chicago Press, 1991. cap. 1.

DOWDING, K. Model or metaphor? A critical review of the policy network approach. Oxford: Black Well Publishers. Political Studies, v. 43, n. 1, p. 136-158, 1995.

DOWDING, K. There must be end to confusion: policy networks, intellectual fatique, and the need for political science methods courses in British universities. Political Studies, v. 49, n. 1, p. 89-105, 2001. 
EVANS, M. Understanding dialectics in policy network analysis. Political Studies, v. 49, n. 1, p. 542-550, 2001.

GOVERNO do Estado de Mato Grosso do Sul; Universidade Federal de Mato Grosso do Sul; Fundação Cândido Rondon. Estudo das cadeias produtivas do Mato Grosso do Sul: Leite. Campo Grande/MS, 2003. Mimeo. 138 p.

GRANOVETTER, M. Economic action and social structure: the problem of embeddedness. American Journal of Sociology, v. 91, n. 3, p. 481-510, 1985.

GUANABARA, R. Comissões parlamentares de inquérito: forma de controle da administração pública. Revista de Administração Pública, v. 33, n. 2, p. 39-65, 1999.

HALL, P.; TAYLOR, R. Political Science and the three new institutionalisms. Political Studies, v. 44, n. 5, p. 936-957, 1996.

IMMERGUT, E. The theoretical core of the new institutionalism. Politics \& Society, v. 26, n. 1, p. 5-34, 1998.

LEITE fica mais barato nos supermercados. Folha do Povo, Campo Grande, 30.10.2001, Economia, p. B-3.

LIMA FILHO, D. O.; FIGUEIREDO, J. C.; PIRES NETO, P. R. A teoria dos custos de transação e a CPI do Leite. In: CONGRESSO BRASILEIRO DE ECONOMIA E SOCIOLOGIA RURAL, 41, Anais. Juiz de Fora: Embrapa Gado de Leite, 2003.

LINDBLOM, C. Política e mercados: os sistemas políticos e econômicos do mundo. Rio de Janeiro: Zahar, 1979.

MARCH, J. G.; OLSEN, J. P. El nuevo institucionalismo: factores organizativos de la vida política. Zona Abierta, n. 63/64, p. 1-43, 1993.

MARSH, D.; SMITH, M. Understanding policy networks: towards a dialectical approach. Political Studies, v. 48, n. 1, p. 4-21, 2000.

MATO Grosso do Sul. Assembléia Legislativa. Relatório Final da CPI do Leite. Campo Grande: 2002. 21 p. 
MERCOESTE. Perfil competitivo do Estado de Mato Grosso do Sul. Mercoeste-Mato Grosso do Sul, Brasília, 2002. 196 p. (Projeto Alavancagem do Mercoeste, do SENAI CO-9802)

MEYER, J. W.; ROWAN, B. Institutionalized organizations: formal structure as myth and ceremony. In: POWELL, W.; DIMAGGIO, P. J. (Org.) The new institutionalism in organizational analysis. Chicago: The University of Chicago Press, 1991. cap. 2.

MEYER, M. W.; ZUCKER, L. Permanently failing organizations. Newbury Park: Sage, 1989.

MICHELS, I.; SABADIN, C.; OLIVEIRA; E. Leite. Campo Grande: UFMS, 2003. Coleção Cadeias Produtivas de Mato Grosso do Sul.

NORTH. D. Institutions, institutional change and economic performance. Cambridge: Cambridge University Press, 1990.

PAULILLO, L. F. Análise organizacional em redes de recursos de poder: contribuições para os estudos da concorrência, das decisões estratégicas e das políticas públicas. In: FUSCO, J. P. Temas emergentes em engenharia de produção. São Paulo: Arte \& Ciência, 2002. p. 27-58.

PAULILLO, L. F. Redes de poder \& territórios produtivos: indústria, citricultura e políticas públicas no Brasil do século XX. São Carlos: RIMA/EdUFSCar, 2000.

POLDONY, J. M.; PAGE, K. L. Networks forms of organization. Annual Review of Sociology, v. 24, p. 57-76, 1998.

POWELL, W. W. Neither market nor hierarchy: networks forms of organization. Research in Organizational Behavior, v. 12, p. 295-336, 1990.

POWELL, W.; SMITH-DOERR, L. Networks and economic life. In: SMELSER, N. J.; SWEDBERG, R. (Eds.) The handbook of economic sociology. Princeton: Princeton University Press, 1994. 
REED, M. Teorização organizacional: um campo historicamente contestado. In: CLEGG, S.; HARDY, C.; NORD, W. R. Handbook de estudos organizacionais. São Paulo: Atlas, 1998. cap. 1.

RHODES, R. A W. Policy networks: a British perspective. Journal of Theoretical Politics, v. 2, n. 3, p. 293-317, 1990.

RHODES, R. A. W. The national world of local government. London: George Allen \& Unwin, 1986.

RHODES, R. A W.; MARSH, D. New directions in the study of policy networks. European Journal of Political Research, v. 21, n. 3, p. 181-205, 1992.

ROMANO, J. O. Interesses privados na formulação e implementação de políticas públicas para a agricultura. In: SILVA, F. C. T.; SANTOS, R.; COSTA, L. F. C. Mundo rural e política: ensaios interdisciplinares. Rio de Janeiro: Campus, 1999. cap. 11.

SCHUMPETER, J. Capitalismo, socialismo e democracia. Rio de Janeiro: Zahar, 1984 [1946].

SKOCPOL, T. Bringing the state back in: current research. In: EVANS, P. B.; RUESCHEMEYER, D.; SKOCPOL, T. Bringing the state back in. Cambridge: Cambridge University Press, 1992. cap. 1.

SMITH, M. The politics of agricultural support in Britain. Aldershot, UK: Dartmouth, 1990.

THÉRET, B. As instituições entre as estruturas e as ações. Lua Nova, n. 58, p. 225-254, 2003.

VAREJO é responsabilizado pela crise do leite em MS. Correio do Estado, Campo Grande, 26.10. 2001, Caderno A, p. 4.

VEBLEN, T. The theory of business enterprise. Reprint. Clifton, NJ; Augustus M. Kelley, 1975 [1904]. 
WAARDEN, F. Dimensions and types of policy networks. European Journal of Political Research, v. 21, n. 1-2, p. 29-52, 1992.

WEBER, M. Economía y sociedad. Buenos Aires: Fondo de Cultura Económica, 1992 [1946].

Artigo recebido em 26/08/2009. Aprovado em 25/11/2009. 